\title{
SorghumBase: a web-based portal for sorghum genetic information and community advancement
}

\author{
Nicholas Gladman ${ }^{1}$ - Andrew Olson ${ }^{1} \cdot$ Sharon Wei ${ }^{1} \cdot$ Kapeel Chougule $^{1} \cdot$ Zhenyuan Lu $^{1} \cdot$ Marcela Tello-Ruiz $^{1}$. \\ Ivar Meijs ${ }^{1}$. Peter Van Buren ${ }^{1}$ - Yinping Jiao ${ }^{3}$. Bo Wang ${ }^{1}$ - Vivek Kumar ${ }^{1}$. Sunita Kumari ${ }^{1}$. Lifang Zhang ${ }^{1}$. \\ John Burke ${ }^{2}$ Junping Chen ${ }^{2}$. Gloria Burow ${ }^{2} \cdot$ Chad Hayes $^{2} \cdot$ Yves Emendack $^{2} \cdot$ Zhanguo Xin $^{2}$. Doreen Ware ${ }^{1,4}$ (i)
}

Received: 7 October 2021 / Accepted: 27 December 2021 / Published online: 11 January 2022

This is a U.S. government work and not under copyright protection in the U.S.; foreign copyright protection may apply 2022

\begin{abstract}
Main conclusion SorghumBase provides a community portal that integrates genetic, genomic, and breeding resources for sorghum germplasm improvement.

Abstract Public research and development in agriculture rely on proper data and resource sharing within stakeholder communities. For plant breeders, agronomists, molecular biologists, geneticists, and bioinformaticians, centralizing desirable data into a user-friendly hub for crop systems is essential for successful collaborations and breakthroughs in germplasm development. Here, we present the SorghumBase web portal (https://www.sorghumbase.org), a resource for the sorghum research community. SorghumBase hosts a wide range of sorghum genomic information in a modular framework, built with open-source software, to provide a sustainable platform. This initial release of SorghumBase includes: (1) five sorghum reference genome assemblies in a pan-genome browser; (2) genetic variant information for natural diversity panels and ethyl methanesulfonate (EMS)-induced mutant populations; (3) search interface and integrated views of various data types; (4) links supporting interconnectivity with other repositories including genebank, QTL, and gene expression databases; and (5) a content management system to support access to community news and training materials. SorghumBase offers sorghum investigators improved data collation and access that will facilitate the growth of a robust research community to support genomics-assisted breeding.
\end{abstract}

Keywords Genomic $\cdot$ Genetic $\cdot$ Molecular $\cdot$ Breeding $\cdot$ Resource $\cdot$ Sorghum

Communicated by Anastasios Melis.

\footnotetext{
Doreen Ware

ware@cshl.edu

1 Cold Spring Harbor Laboratory, Cold Spring Harbor, NY 11724, USA

2 Plant Stress and Germplasm Development Unit, Cropping Systems Research Laboratory, U.S. Department of Agriculture-Agricultural Research Service, Lubbock, TX 79415, USA

3 Department of Plant and Soil Science, Institute of Genomics for Crop Abiotic Stress Tolerance, Texas Tech University, Lubbock, TX 79409, USA

4 U.S. Department of Agriculture-Agricultural Research Service, NEA Robert W. Holley Center for Agriculture and Health, Cornell University, Ithaca, NY 14853, USA
}

\section{Background}

Sorghum [Sorghum bicolor (L.) Moench], domesticated in Northern Africa 6000 years ago, comprises five major botanical races: bicolor, durra, guinea, caudatum, and kafir (Wet et al. 1967; Dillon et al. 2007). A C 4 grass crop with tolerances to drought, heat, low nutrients, and highsalt conditions (Doumbia et al. 1993, 1998; Leiser et al. 2014; Hufnagel et al. 2014; Tack et al. 2017; Ochieng et al. 2021); sorghum is the fifth most important crop worldwide relating to acreage and production. Sorghum cultivars are grown for grain, silage, biomass, or syrup production. Historically, sorghum was predominantly used as feed and fodder for livestock, but since the mid-2010s, the amount used for the consumer food industry has risen $>250 \%$ (https:// www.sorghumcheckoff.com/resources/research). Since the 1960s, global production of sorghum has increased, even 
while dedicated land use has decreased (http://www.fao.org/ faostat/en/\#data).

Sorghum is a useful model for crop research due to its compact genome; the first completely sequenced reference genome, BTx623, is $730 \mathrm{Mb}$ (Paterson et al. 2009; McCormick et al. 2018; Cooper et al. 2019). Sorghum shares functional genomic capabilities of agricultural plant systems such as maize, but compared to maize, most domesticated sorghum lines have fewer deleterious mutations relative to wild landraces (Lozano et al. 2021), likely due to a hermaphroditic inflorescence and the higher incidence of selfing (> 80\%) (Djè et al. 2004; Barnaud et al. 2008) during germplasm selection, conversion, and improvement (Lai et al. 2018).

As climate change progresses and arable land becomes limited (Intergovernmental Panel on Climate Change 2014), sorghum serves as an essential crop for addressing the challenge of feeding an ever-increasing world population. Global germplasm repositories such as the International Crops Research Institute for the Semi-Arid Tropics (ICRISAT; http://genebank.icrisat.org/) and the Germplasm Resource Information Network (GRIN; https://npgsweb.ars-grin.gov/ gringlobal) house tens of thousands of domesticated sorghum cultivars and wild landraces comprising vast genetic potential for use in yield improvement in diverse farming operations. Core germplasm collections such as the Sorghum Association Panel (Casa et al. 2008), Bioenergy Association Panel (Brenton et al. 2016), and Nested Association Mapping population (Bouchet et al. 2017; Boatwright et al. 2021; Perumal et al. 2021) were created to enable breeders and geneticists to dissect the molecular underpinnings of traits including grain yield, nutrient use efficiency (Shakoor et al. 2016), and disease resistance (Cuevas et al. 2019). Complementing these resources, the genomes of many important lines have been sequenced (BTx623, Rio, Tx2783, RTx436, and RTx430), with dozens more on the way, constituting a sorghum pan-genome dataset with myriad potential applications.

Here, we describe SorghumBase (https://www.sorgh umbase.org), a web-based community resource designed as an access point for the sorghum genomic/molecular research and breeding community.

\section{Introduction to SorghumBase portal}

SorghumBase is a genomic resource for the sorghum community, stably funded by the United States Department of Agriculture (USDA) just like MaizeGDB (Woodhouse et al. 2021), GrainGenes (Blake et al. 2019), and Soybase (Grant et al. 2010). This resource was developed to support stewardship and sharing of emergent sorghum genomic and genetic data, with the goal of accelerating knowledge accumulation associated with high-value traits by harnessing genomic, genetic, and functional information generated by the sorghum research community. SorghumBase follows findability, accessibility, interoperability, and reusability (FAIR) guidelines (Wilkinson et al. 2016). The foundations of SorghumBase focus on improving management of genomic related data sets, while promoting standards, open access to data, and information sharing with the broader community. The top priority for SorghumBase is stewardship of sorghum reference genomes: a cornerstone for accessing and characterizing allelic variation underlying important agronomic traits. The portal uses Ensembl and Gramene open-source software (Kersey et al. 2018; Tello-Ruiz et al. 2021), representing more than 23 years of development of data models, workflows, robust visualizations, and application interfaces (APIs).

\section{Sorghum genomes}

The first public release includes five public reference assemblies along with the community annotations for BTx623 (McCormick et al. 2018), Tx2783 (Wang et al. 2021), RTx430 (Deschamps et al. 2018), RTx436 (Wang et al. 2021), and Rio (Cooper et al. 2019) (Table 1). For each genome, information on the assembly method and gene structural annotations is available from the home page of its individual genome browser. No standard nomenclature has yet been established for sorghum genes, transcripts, and proteins; instead, each community project uses its own naming assignments. SorghumBase stores reference genome assemblies, gene structures, and functional annotations of the genomes in an Ensembl genome core database. Ensembl data models and APIs have specific requirements, in agreement with International Nucleotide Sequence Database Collaboration (INSDC) gene annotation standards, for stable database identifiers that sometimes conflict with or require changes to existing community annotations. For example, Phytozome (Goodstein et al. 2012) has historically given sorghum genes names like 'Sobic.004G141800', which conflicts with INSDC standards. SorghumBase and EnsemblPlants (Howe et al. 2020) resolve this problem by assigning Phytozome names as synonyms while storing compliant names as the gene stable ID in the database. The Phytozome gene ID above is stored as 'SORBI_3004G141800', where 'SORBI_3' represents the species or germplasm name (SORBI for Sorghum bicolor) and assembly version. The rest of the identifier includes the chromosome on which the gene is located (004), followed by the identifier ' $G$ ' for gene and then a locus index based on the sequential order of loci on the chromosome $(141,800)$. The project will work with the sorghum community to ensure that sorghum genome assemblies are in the correct format to support accessioning 
Table 1 Current pan-genome content and annotations

\begin{tabular}{|c|c|c|c|c|c|}
\hline & ВТх623 v3.1 & Tx2783 & RTx436 & TX430 v2 & Rio v2.1 \\
\hline Gene count & 34,118 & 29,612 & 29,265 & 36,937 & 35,490 \\
\hline Gene length (ave) & 3714 & 3833 & 3900 & 3252 & 3322 \\
\hline Gene length (median) & 2824 & 2888 & 2917 & 2217 & 2469 \\
\hline Exon count & 154,042 & 147,196 & 146,857 & 163,854 & 163,465 \\
\hline Exon length (ave) & 449 & 357 & 353 & 348 & 353 \\
\hline Exon length (median) & 176.5 & 172 & 171 & 174 & 172 \\
\hline Intron count & 119,924 & 117,584 & 117,592 & 126,917 & 127,975 \\
\hline Intron length (ave) & 454 & 512 & 514 & 483 & 467 \\
\hline Intron length (median) & 142 & 150 & 150 & 147 & 146 \\
\hline CDS count & 47,110 & 35,998 & 41,713 & 49,928 & 41,048 \\
\hline CDS length (ave)* & 842 & 980 & 838 & 858 & 964 \\
\hline CDS length (median)* & 981 & 1005 & 1002 & 981 & 939 \\
\hline Peptide count & 47,110 & 35,998 & 41,713 & 49,928 & 41,048 \\
\hline Peptide length (ave)* & 281 & 327 & 279 & 286 & 321 \\
\hline Peptide length (median)* & 327 & 335 & 334 & 327 & 313 \\
\hline Five_prime_UTR count & 25,100 & 32,455 & 30,983 & 22,796 & 30,096 \\
\hline Five_prime_UTR length (ave) & 484 & 197 & 196 & 225 & 202 \\
\hline Five_prime_UTR length (median) & 207 & 147 & 143 & 171 & 144 \\
\hline Three_prime_UTR count & 26,660 & 29,444 & 29,109 & 22,761 & 30,239 \\
\hline Three_prime_UTR length (ave) & 653 & 371 & 374 & 399 & 396 \\
\hline Three_prime_UTR length (median) & 356 & 318 & 314 & 339 & 339 \\
\hline Exons per transcript (ave) & 4.5 & 5 & 5 & 4.4 & 4.6 \\
\hline Single-exon gene count (pct) & $8467(24.8)$ & $6783(22.9)$ & $6585(22.5)$ & $11,854(32.1)$ & 8128 (22.9) \\
\hline
\end{tabular}

Genome assembly and annotation descriptions of BTx623, Tx2783, RTx436, Tx430, and Rio. All currently available for analysis on SorghumBase

*Note: longest_CDS_transcript_used_for_calculation_of_CDS_and_Protein_length_statistics by one of the archives in the INSDC (http://www.insdc.org), e.g., the European Nucleotide Archive (ENA) from EMBLEBI or the NCBI databases.

\section{Phylogenetic gene trees}

Genome cores provide the foundation for building protein-based gene trees. In Release 1, we used five sorghum genomes as inputs for the protein-based gene trees for Ensembl Protein Comparative phylogenetic analysis (version-87, https://doi.org/10.1093/database/bav096) and seven outgroups [Arabidopsis thaliana (TAIR10) (Berardini et al. 2015), Oryza sativa (IRGSP-1.0) (Kawahara et al. 2013), Vitis vinifera (IGGP_12x) (Jaillon et al. 2007), B73 Zea mays (AGPv4) (Jiao et al. 2017)], Chlamydomonas reinhardtii (Chlamydomonas_reinhardtii_ v5.5) (Merchant et al. 2007), Selaginella moellendorffii (v1.0) (Banks et al. 2011), and Drosophila melanogaster (BDGP6) (dos Santos et al. 2015). The resultant analyses had 21,429 protein-coding gene family trees, constructed using the peptide encoded by the canonical transcript (i.e., a representative transcript for a given gene) of each
317,845 individual genes (350,099 input proteins) from the 12 genomes. These gene trees provide the framework for phylogenomic dating of sorghum genes and establishment of orthologs and paralogs, facilitating movement between and within species as well as characterization of the species pan-gene set (Fig. 1). The gene trees provide the input for building homology views that are available from the gene search. The gene trees and position information for each gene are used to generate gene neighborhood views. In Fig. 1A, the BTx623 sorghum gene SORBI_3006G095600 is central, and the local neighborhood is expanded to ten genes on either side. Genes are color-coded based on the trees to which they belong. All five sorghum genomes have a candidate allele of the SORBI_3006G095600 homolog. The gene neighborhoods are similar: Tx2783 and Tx436 have an additional gene, indicated by the gray icon. Figure 1B demonstrates the genome browser function with various user-customizable genomic data tracks, including positions of SNPs from ethyl methanesulfonate (EMS) and natural variant populations. Figure 2A shows the available SNP populations that lie around the MSD2 gene model; researchers can select mutations with a higher probability of deleterious impact 


\section{(a)}

SORGHUMBASE 。

\section{GENES SEARCH}
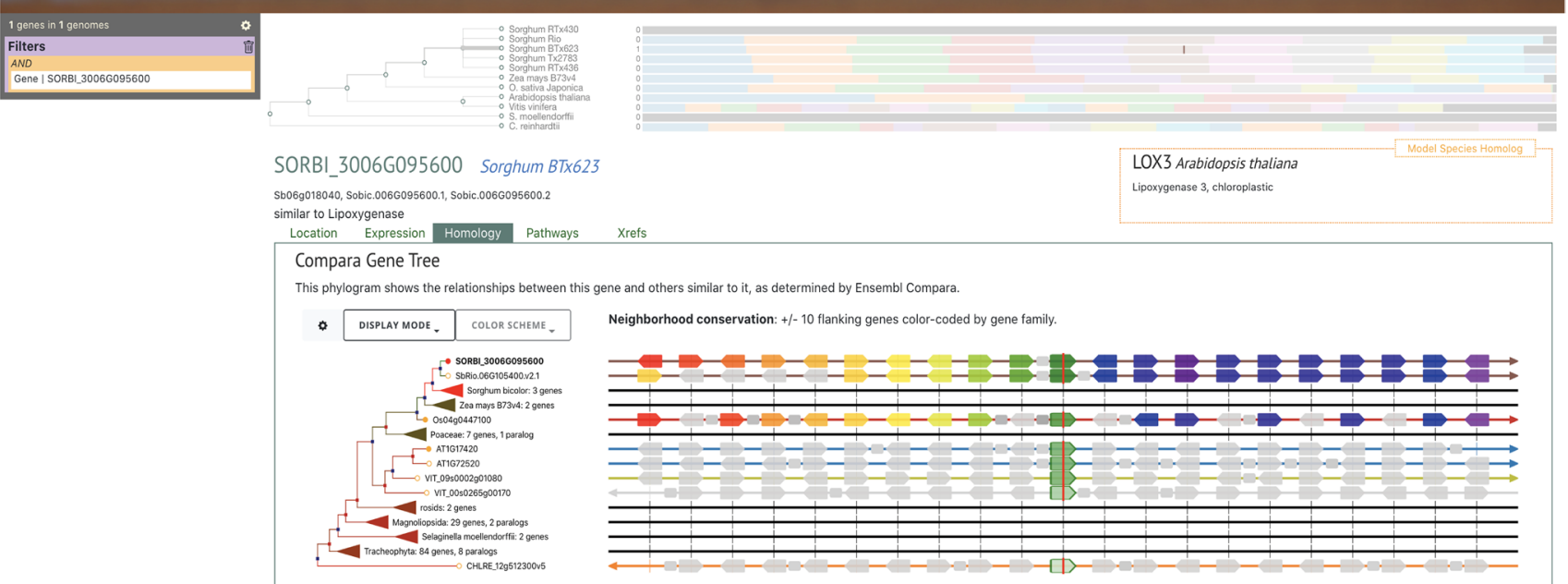

LOX3 Arabidopsis thaliana

Lipoxygenase 3 , chloroplastic

Xrefs

Dethers similar to it, as determined by Ensembl Compara.

Neighborhood conservation: + - 10 flanking genes color-coded by gene family

Search Filters

\begin{tabular}{|c|c|c|}
\hline GENE TREE | HOMOLOGS WIITS & GENE TREE | ORTHOLOGS (10) & GENE TREF | PARALOGS (1) \\
\hline
\end{tabular}

\section{(9) USDA}

(b)

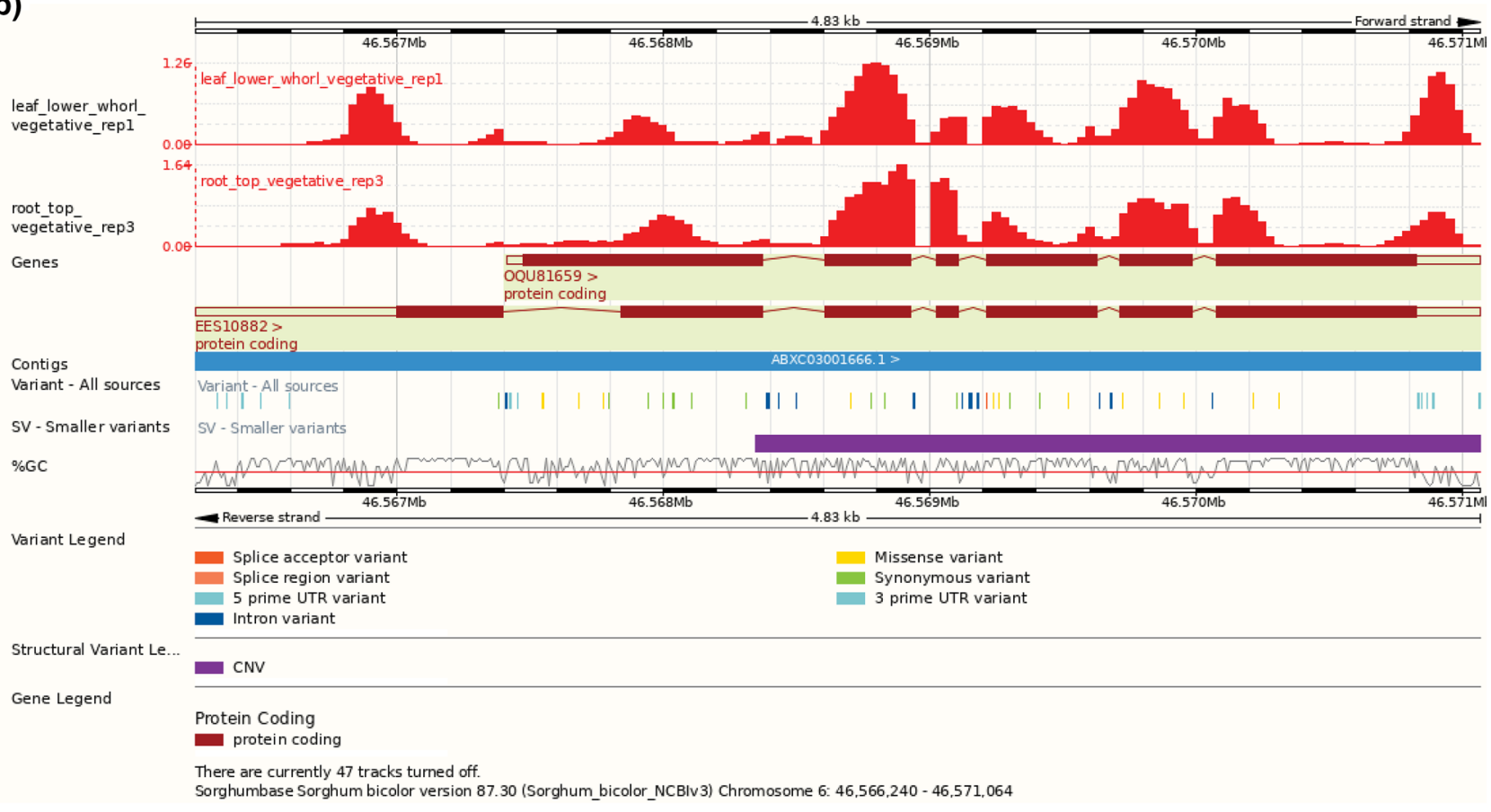

Fig. 1 SorghumBase portal functionality. A Gene search results for the sorghum MSD2 gene; result page displays gene tree views and has changeable genome features and quick-views of available expression and metabolic data. B Ensembl browser view displaying epigenetic marks as well as cataloged SNP and structural variants associated with the surrounding gene models 
(a)

\begin{tabular}{|c|c|c|c|c|c|}
\hline tmp_6_47487513_G_A & $6: 46569212$ & $\mathrm{G} / \mathrm{A}$ & SNP & $\begin{array}{l}\text { Sorghum_EMS__ } \\
\text { mutants }\end{array}$ & $\begin{array}{l}\text { | Splice acceptor } \\
\text { varíant }\end{array}$ \\
\hline tmp_6_47487541_C_T & $6: 46569240$ & $\mathrm{C} / \mathrm{T}$ & SNP & $\begin{array}{l}\text { Sorghum_EMS_ } \\
\text { mutants }\end{array}$ & Missense variant \\
\hline tmp_6_47487559_C_G & $6: 46569258$ & $\mathrm{C} / \mathrm{G}$ & SNP & Mace_2013 & Missense variant \\
\hline tmp_6_47487603_C_T & $6: 46569302$ & $\mathrm{C} / \mathrm{T}$ & SNP & $\begin{array}{l}\text { Sorghum_EMS_ } \\
\text { mutants }\end{array}$ & $\begin{array}{l}\text { | Synonymous } \\
\text { variant }\end{array}$ \\
\hline Imp_6_47487714_C_I & $6: 46569413$ & $\mathrm{C} / \mathrm{T}$ & SNP & $\begin{array}{l}\text { Sorghum_EMS_ } \\
\text { mutants }\end{array}$ & $\begin{array}{l}\text { | Synonymous } \\
\text { variant }\end{array}$ \\
\hline tmp_6_47487823_G_A & $6: 46569522$ & $\mathrm{G} / \mathrm{A}$ & SNP & $\begin{array}{l}\text { Sorghum_EMS_ } \\
\text { mutants }\end{array}$ & Missense variant \\
\hline tmp_6_47487939_A_T & $6: 46569638$ & $\mathrm{~A} T \mathrm{~T}$ & SNP & Mace_2013 & | Intron variant \\
\hline tmp $6 \_47487982 \_$A G & $6: 46569681$ & $A G$ & SNP & Mace_2013 & | Intron variant \\
\hline tmp_6_47488026_C_T & $6: 46569725$ & $\mathrm{C} / \mathrm{T}$ & SNP & $\begin{array}{l}\text { Sorghum_EMS_ } \\
\text { mutants }\end{array}$ & Missense variant \\
\hline Imp_6_47488163_G_A & $6: 46569862$ & $\mathrm{G} / \mathrm{A}$ & SNP & $\begin{array}{l}\text { Sorghum_EMS_ } \\
\text { mutants }\end{array}$ & Missense variant \\
\hline tmp_6_47488256_G_A & $6: 46569955$ & $\mathrm{G} / \mathrm{A}$ & SNP & $\begin{array}{l}\text { Sorghum_EMS_ } \\
\text { mutants }\end{array}$ & Missense variant \\
\hline tmp_6_47488361_C_G & $6: 46570060$ & $C / G$ & SNP & Mace_2013 & | Intron variant \\
\hline$\underline{\text { S6 } 6 \text { 47488517 }}$ & $6: 46570216$ & $\mathrm{G} / \mathrm{C}$ & SNP & Morris 2013 & Missense variant \\
\hline tmp_6_47488613_C_T & $6: 46570312$ & $\mathrm{C} / \mathrm{T}$ & SNP & $\begin{array}{l}\text { Sorghum_EMS_ } \\
\text { mutants }\end{array}$ & Missense variant \\
\hline tmp_6_47489133_TC & $6: 46570832$ & $T / C$ & SNP & Mace_2013 & | 3 prime UTR variant \\
\hline
\end{tabular}

(b)

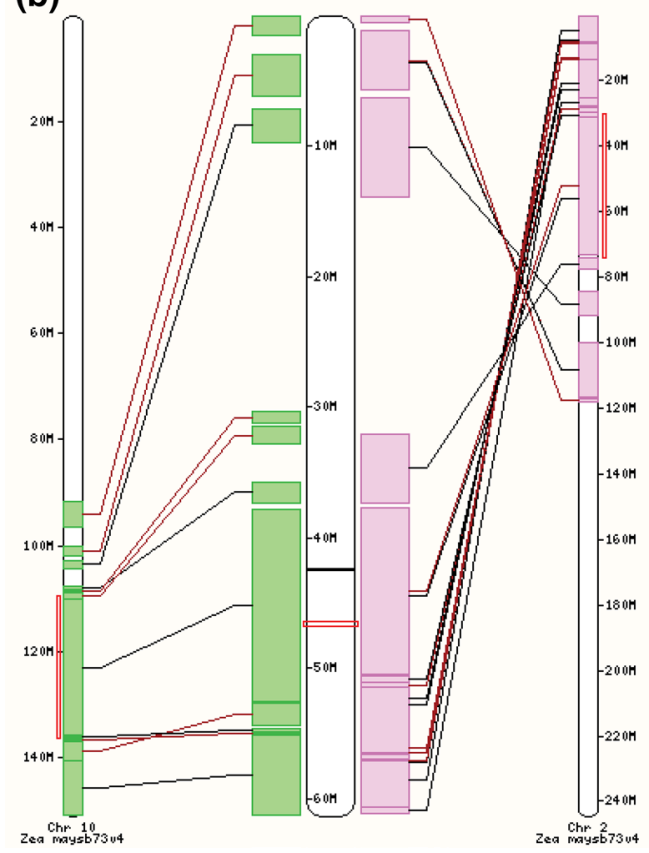

Fig. 2 SorghumBase data visualizations. A Variant table displaying EMS-induced SNPs for MSD2, colorized for mutation consequence; the table can be filtered for SIFT score. B Synteny between Sorghum BTx623 v3 and Zea mays v4 chromosome assemblies

on gene function via SIFT scores. For breeding purposes, the high degree of gene order conservation with rice and maize can be visualized through syntenic comparisons; one of the two orthologous regions of maize exhibits a lower level of conservation than the other (Fig. 2B). Expansion of the leaves on the trees reveals 12 paralogs of MSD2 in the sorghum BTx623 genome, as seen by the paralogs tab at the display bottom.

\section{Sorghum genetic variation}

SorghumBase contains variant data for SNPs and structural variants. Although SorghumBase is a pan-genome resource, BTx623 serves as the primary reference coordinate for calling genetic variations and pathway projections. Release 1.0 contains SNPs from natural (Mace et al. 2013; Morris et al. 2013) and EMS-induced populations (Jiao et al. 2016). These combined datasets comprise over 8.5 million SNPs covering $>85 \%$ of the initial reference genome and $>95 \%$ of gene space, creating a rich resource for forward and reverse genetic analysis. The genetic variation data are stored in an Ensembl variation database. The Ensembl variation effect predictor (VEP) (McLaren et al. 2016) is used to predict impacts on gene products through SIFT scores (Kumar et al. 2009). The impacts of the SNPs can be viewed in the genome browser tracks and are also listed by SIFT scores and color-coded in table format (Figs. 1B, 2A).

\section{Phenotypes}

SorghumBase currently hosts two types of phenotype data: quantitative trait loci (QTLs) (Mace et al. 2019) and gene expression (Papatheodorou et al. 2020). The QTL data are directly imported from the Sorghum QTL Atlas (https:// aussorgm.org.au/sorghum-qtl-atlas/) in collaboration with the University of Queensland and Research Facilities of the Department of Agriculture and Fisheries. Intended as an applied breeding resource, this platform contains data from more than 150 QTL and GWAS studies for $>200$ unique traits classified into seven broad categories: stem morphology, stem composition, leaf, panicle, abiotic resistance, biotic resistance, and maturity [modified from Mace and Jordan (2011)]. In the SorghumBase first release, the QTL data are available as genome browser tracks, allowing the user to identify candidate genes underlying QTLs. A dropdown in the genome browser menu contains links back to the Sorghum QTL Atlas, providing interoperability between sorghum community resources. Gene expression data are directly imported from the EBI Gene Expression Atlas. These profiles cover 24 different tissues and abiotic stress conditions (Supplemental Table 1) (Papatheodorou et al. 2020) and can be viewed as transcripts per million 
(TPM) heatmaps for individually searched genes; individual experiments can also be downloaded directly from the linked EBI portal. This allows users to simultaneously visualize gene expression data for multiple tissues and rapidly winnow candidate loci.

\section{Public engagement, outreach, and training}

We engage the community through webinars, surveys, individual exchanges, and in-person meetings. In addition, we host virtual office hours and a real-time messaging service (e.g., Slack). The SorghumBase content management system (CMS) was built using the WordPress platform. Team members and authorized contributors are able to use a simplified interface to create web pages, add content, and customize designs through the CMS dashboard. As of publication, there are five blog posts, five news items, and five research notes. In addition, the platform has a quick-start guide to orient users with existing tools and datasets (https://sorgh umbase.org/guides).

\section{Future directions}

Although SorghumBase serves as a nexus for valuable data, its continued success as a facilitator and launching point for research and collaboration ultimately relies upon the engagement of the sorghum community. Of utmost consideration are scaling genomes for future pan-genome inclusion and creating sufficient browser visualizations to enable ease of use. These efforts, in turn, are reliant on proper functional genomic annotations and amalgamation of priority genomes and trait-based data, such as core and dispensable genomes within the pan-genome, disease-resistance loci, QTL and GWAS integration, etc. Integration of these emerging data sets will accelerate insights into allelic variation and agronomically important traits. Our future plans include working closely with the community to establish rigorous standards for data cataloging and dissemination and growing the pangenome. Prioritizing germplasm for future inclusion for the pan-genome will become crucial for researchers and stakeholders, and will be prioritized based on agricultural potential of the lines and quality of the reference assembly. We plan to establish working groups to improve gene annotation, genomic data collection, and engage community contributors to author research notes and news on the site. In addition to the quick-start guide and our first video tutorial on the SorghumBase search interface, including the homology views in the search results (e.g., gene neighborhood views), we plan to develop additional training materials on the Ensembl browser and BLAST alignment tools. Ultimately, SorghumBase is intended to morph around current community needs while accurately pursuing future projects that will capitalize on the larger arc of agricultural trends.

Author contribution statement AO, SW, KC, MTR, ZL, IM, PVB, SK, and VK contributed to website construction, organization, and staging of datasets. AO and SW implemented the data visualizations. $\mathrm{KC}, \mathrm{IM}, \mathrm{SK}, \mathrm{BW}, \mathrm{YJ}$, and VK assisted with the data organization. NG, JB, JC, GB, $\mathrm{CH}, \mathrm{YE}, \mathrm{LZ}, \mathrm{YJ}, \mathrm{BW}$, and ZX contributed to site usability, use cases, data curation, and content inclusion. NG, AO, MTR, SW, KC, ZX, and DW drafted the manuscript. All authors reviewed the manuscript.

Supplementary Information The online version contains supplementary material available at https://doi.org/10.1007/s00425-022-03821-6.

Acknowledgements We thank the sorghum community members, domestic and international, for initial discussions about community needs, contribution of data sets, and feedback on the site. We acknowledge the SorghumBase scientific advisory committee, National Sorghum Producers (https://sorghumgrowers.com), and Sorghum Checkoff (https://www.sorghumcheckoff.com/) for their support and feedback. We acknowledge Demitri Muna and Liya Wang for their contributions and feedback. SorghumBase was funded through the United States Department of Agriculture grant USDA-ARS 8062-21000-041-00D. This work was performed with assistance from the US National Institutes of Health Grant S10OD028632-01.

Data availability All datasets described in this article have been previously published, are publicly available, and can be found linked from https://www.sorghumbase.org.

Open Access This article is licensed under a Creative Commons Attribution 4.0 International License, which permits use, sharing, adaptation, distribution and reproduction in any medium or format, as long as you give appropriate credit to the original author(s) and the source, provide a link to the Creative Commons licence, and indicate if changes were made. The images or other third party material in this article are included in the article's Creative Commons licence, unless indicated otherwise in a credit line to the material. If material is not included in the article's Creative Commons licence and your intended use is not permitted by statutory regulation or exceeds the permitted use, you will need to obtain permission directly from the copyright holder. To view a copy of this licence, visit http://creativecommons.org/licenses/by/4.0/.

\section{References}

Banks JA, Nishiyama T, Hasebe M et al (2011) The Selaginella genome identifies genetic changes associated with the evolution of vascular plants. Science 332:960-963

Barnaud A, Trigueros G, McKey D, Joly HI (2008) High outcrossing rates in fields with mixed sorghum landraces: how are landraces maintained? Heredity 101:445-452

Berardini TZ, Reiser L, Li D et al (2015) The Arabidopsis information resource: making and mining the "gold standard" annotated reference plant genome. Genesis 53:474-485

Blake VC, Woodhouse MR, Lazo GR et al (2019) GrainGenes: centralized small grain resources and digital platform for geneticists and breeders. Database. https://doi.org/10.1093/database/baz065 
Boatwright JL, Brenton ZW, Boyles RE et al (2021) Genetic characterization of a Sorghum bicolor multiparent mapping population emphasizing carbon-partitioning dynamics. G3. https://doi.org/ 10.1093/g3journal/jkab060

Bouchet S, Olatoye MO, Marla SR et al (2017) Increased power to dissect adaptive traits in global sorghum diversity using a nested association mapping population. Genetics 206:573-585

Brenton ZW, Cooper EA, Myers MT et al (2016) A genomic resource for the development, improvement, and exploitation of sorghum for bioenergy. Genetics 204:21-33

Casa AM, Pressoir G, Brown PJ et al (2008) Community resources and strategies for association mapping in sorghum. Crop Sci 48:30-40

Cooper EA, Brenton ZW, Flinn BS et al (2019) A new reference genome for Sorghum bicolor reveals high levels of sequence similarity between sweet and grain genotypes: implications for the genetics of sugar metabolism. BMC Genomics 20:420

Cuevas HE, Fermin-Pérez RA, Prom LK et al (2019) Genome-wide association mapping of grain mold resistance in the US Sorghum Association Panel. Plant Genome. https://doi.org/10.3835/plant genome2018.09.0070

de Wet JMJ, de Wet JMJ, Huckabay JP (1967) The origin of Sorghum bicolor. II. Distribution and domestication. Evolution 21:787

Deschamps S, Zhang Y, Llaca V et al (2018) A chromosome-scale assembly of the sorghum genome using nanopore sequencing and optical mapping. Nat Commun 9:4844

Dillon SL, Shapter FM, Henry RJ et al (2007) Domestication to crop improvement: genetic resources for Sorghum and Saccharum (Andropogoneae). Ann Bot 100:975-989

Djè Y, Heuertz M, Ater M et al (2004) In situ estimation of outcrossing rate in sorghum landraces using microsatellite markers. Euphytica 138:205-212

dos Santos G, Schroeder AJ, Goodman JL et al (2015) FlyBase: introduction of the Drosophila melanogaster Release 6 reference genome assembly and large-scale migration of genome annotations. Nucleic Acids Res 43:D690-D697

Doumbia MD, Hossner LR, Onken AB (1993) Variable sorghum growth in acid soils of subhumid West Africa. Arid Soil Res Rehabil 7:335-346

Doumbia MD, Hossner LR, Onken AB (1998) Sorghum growth in acid soils of West Africa: variations in soil chemical properties. Arid Soil Res Rehabil 12:179-190

Goodstein DM, Shu S, Howson R et al (2012) Phytozome: a comparative platform for green plant genomics. Nucleic Acids Res 40:D1178-D1186

Grant D, Nelson RT, Cannon SB, Shoemaker RC (2010) SoyBase, the USDA-ARS soybean genetics and genomics database. Nucleic Acids Res 38:D843-D846

Howe KL, Contreras-Moreira B, De Silva N et al (2020) Ensembl Genomes 2020-enabling non-vertebrate genomic research. Nucleic Acids Res 48:D689-D695

Hufnagel B, de Sousa SM, Assis L et al (2014) Duplicate and conquer: multiple homologs of PHOSPHORUS-STARVATION TOLERANCE1 enhance phosphorus acquisition and sorghum performance on low-phosphorus soils. Plant Physiol 166:659-677

Intergovernmental Panel on Climate Change (2014) Climate change 2014: synthesis report (longer report). IPCC

Jaillon O, Aury J-M, Noel B et al (2007) The grapevine genome sequence suggests ancestral hexaploidization in major angiosperm phyla. Nature 449:463-467

Jiao Y, Burke J, Chopra R et al (2016) A sorghum mutant resource as an efficient platform for gene discovery in grasses. Plant Cell 28:1551-1562

Jiao Y, Peluso P, Shi J et al (2017) Improved maize reference genome with single-molecule technologies. Nature 546:524-527
Kawahara Y, de la Bastide M, Hamilton JP et al (2013) Improvement of the Oryza sativa Nipponbare reference genome using next generation sequence and optical map data. Rice 6:4

Kersey PJ, Allen JE, Allot A et al (2018) Ensembl Genomes 2018: an integrated omics infrastructure for non-vertebrate species. Nucleic Acids Res 46:D802-D808

Kumar P, Henikoff S, Ng PC (2009) Predicting the effects of coding non-synonymous variants on protein function using the SIFT algorithm. Nat Protoc 4:1073-1081

Lai X, Yan L, Lu Y, Schnable JC (2018) Largely unlinked gene sets targeted by selection for domestication syndrome phenotypes in maize and sorghum. Plant J 93:843-855

Leiser WL, Rattunde HFW, Weltzien E et al (2014) Two in one sweep: aluminum tolerance and grain yield in P-limited soils are associated to the same genomic region in West African sorghum. BMC Plant Biol 14:206

Lozano R, Gazave E, Dos Santos JPR et al (2021) Comparative evolutionary genetics of deleterious load in sorghum and maize. Nat Plants 7:17-24

Mace ES, Jordan DR (2011) Integrating sorghum whole genome sequence information with a compendium of sorghum QTL studies reveals uneven distribution of QTL and of gene-rich regions with significant implications for crop improvement. Theor Appl Genet 123(1):169-191. https://doi.org/10.1007/ s00122-011-1575-y

Mace ES, Tai S, Gilding EK et al (2013) Whole-genome sequencing reveals untapped genetic potential in Africa's indigenous cereal crop sorghum. Nat Commun 4:2320

Mace E, Innes D, Hunt C et al (2019) The Sorghum QTL Atlas: a powerful tool for trait dissection, comparative genomics and crop improvement. Theor Appl Genet 132:751-766

McCormick RF, Truong SK, Sreedasyam A et al (2018) The Sorghum bicolor reference genome: improved assembly, gene annotations, a transcriptome atlas, and signatures of genome organization. Plant J 93:338-354

McLaren W, Gil L, Hunt SE et al (2016) The ensembl variant effect predictor. Genome Biol 17:122

Merchant SS, Prochnik SE, Vallon O et al (2007) The Chlamydomonas genome reveals the evolution of key animal and plant functions. Science 318:245-250

Morris GP, Ramu P, Deshpande SP et al (2013) Population genomic and genome-wide association studies of agroclimatic traits in sorghum. Proc Natl Acad Sci USA 110:453-458

Ochieng G, Ngugi K, Wamalwa LN et al (2021) Novel sources of drought tolerance from landraces and wild sorghum relatives. Crop Sci 61:104-118

Papatheodorou I, Moreno P, Manning J et al (2020) Expression Atlas update: from tissues to single cells. Nucleic Acids Res 48:D77-D83

Paterson AH, Bowers JE, Bruggmann R et al (2009) The Sorghum bicolor genome and the diversification of grasses. Nature 457:551-556

Perumal R, Tesso TT, Morris GP et al (2021) Registration of the sorghum nested association mapping (NAM) population in RTx430 background. J Plant Regist 15:395-402

Shakoor N, Ziegler G, Dilkes BP et al (2016) Integration of experiments across diverse environments identifies the genetic determinants of variation in Sorghum bicolor seed element composition. Plant Physiol 170:1989-1998

Tack J, Lingenfelser J, Jagadish SVK (2017) Disaggregating sorghum yield reductions under warming scenarios exposes narrow genetic diversity in US breeding programs. Proc Natl Acad Sci USA 114:9296-9301

Tello-Ruiz MK, Naithani S, Gupta P et al (2021) Gramene 2021: harnessing the power of comparative genomics and pathways for plant research. Nucleic Acids Res 49:D1452-D1463 
Wang B, Jiao Y, Chougule K et al (2021) Pan-genome analysis in sorghum highlights the extent of genomic variation and sugarcane aphid resistance genes. bioRxiv 2021.01.03.424980

Wilkinson MD, Dumontier M, Aalbersberg IJJ et al (2016) The FAIR guiding principles for scientific data management and stewardship. Sci Data 3:160018

Woodhouse MR, Cannon EK, Portwood JL 2nd et al (2021) A pangenomic approach to genome databases using maize as a model system. BMC Plant Biol 21:385
Publisher's Note Springer Nature remains neutral with regard to jurisdictional claims in published maps and institutional affiliations. 